\title{
EFFECT OF RIVETING ON THE JOINT STRENGTH OF ADHESIVELY BONDED DOUBLE LAP JOINTS
}

\author{
M. Yavuz SOLMAZ ${ }^{1}$, İbrahim KOCABAŞ ${ }^{2,}{ }^{\text {, }}$, Mustafa GÜR ${ }^{1}$ \\ ${ }^{1}$ Mechanical Engineering, Engineering Faculty, Firat University, Elazığ, Turkey \\ ${ }^{2}$ Vocational School of Transportation, Anadolu University, Eskişehir, Turkey
}

\begin{abstract}
The scope of this study is to determine the effectiveness of using rivets in the adhesive joints in order to combine plastic-based composite materials which are often used in today's engineering structures, to the joint strength. For this purpose, double lap joints are prepared in 3 different types of configuration included adhesive, pinned and both adhesive and pinned and also prepared in 3 different overlap lengths as 30,45 and $60 \mathrm{~mm}$. Stress-strain diagrams were derived by exposing the joints obtained, to the axial tensile test and then the most appropriate joint type was determined by comparing each of the results obtained. The evaluation of the results pointed out that the hybrid joints where adhesive and rivet are used together can carry much more load than the joints where the only adhesive was used or the joints which are combined with a rivet in terms of joint strength.
\end{abstract}

Keywords: Double lap joint, Adhesive, Rivet, Overlap length

\section{INTRODUCTION}

Adhesive bonding technology has been studied for many years and it has played an essential role in the development and growth of the rehabilitation and repairing techniques of timber structures involving adhesive joints instead of mechanical joints [1]. Accordingly, it is also possible to endurance these type of connections by considering riveting connections together with adhesives. Generally, the joining methods of the composite structures are classified into the mechanical and adhesive types. The adhesive joints do not require holes, and they distribute the load over a larger area than the mechanical joints; however, they are very sensitive to the surface treatment, service temperature, humidity, and other environmental conditions $[2,3]$.

Amongst the advantages of adhesives, we can highlight their high resistance, (even under unfavourable atmospheric conditions), their lower weight, water tightness and elimination of galvanic corrosion [4, 5]. Besides, the stress distribution over the area of adhesively bonded connections is assumed to be quite complex, which is leading to do very difficult strength and failure predictions numerically. There are various studies concerning stress distribution and behaviour of different adhesive types for double lap joint connections in structural composites and other basic assemblies where not much endurance of joint is required. One of the investigations for this subject was presented by Reis et al. [6] studied the effect of adhesive overlap length on the ultimate joint strength in a numerical-experimental work. They found that the overlap length should be $15-30 \mathrm{~mm}$ and by increasing this length, the values of peel and shear stresses increase. This length would result in the best stress distribution, confirmed by the variation of equivalent stress [7]. A study was performed related to the one-dimensional elastic solution of double lap joints at different overlap lengths by L. Goglio and M.Rossetto. They have claimed that the solution is accurate if elastic properties are taken into account [8]. Yong-Bin Park et al. studied composite lap joint under different environmental conditions and they concluded that high strength can be obtained at low temperatures [9].

*Corresponding Author: ibrahimkocabas@anadolu.edu.tr 
The strength of adhesively bonded joints can be predicted using one of the two methods: (i) stress analysis or (ii) fracture mechanics. According to the stress analysis approach, failure of the adhesive is expressed in terms of a strength failure criteria, such as the maximum stress and maximum strain criteria [10] or strain energy density criteria [11]. In the fracture mechanics approach, failure of the adhesive is expressed in terms of the critical values of strain energy release rate $[12,13]$ or other fracture parameters. Suo and Huchinson [14] analysed the strain energy release rate between two elastic layers, and their cracked-beam model (CBM) has been adopted for the analysis of fracture in single-lap joints [15] and cracked lap-shear joints $[16,17]$. Besides, an experimental study was performed by Min-Gyu Song et al. to determine strength and fracture of adhesively bonded joints with their effects of manufacturing types on the joint strength. And they found that secondary bonded joints had higher strength and failure load, the stacking sequence of the composites was slightly effective in joint strength as well $[18,19]$.

Due to the complex structure of adhesively bonded composite structures reinforced with riveted joints, an experimental method was considered and models were subjected to tension tests for the failure prediction of manufactured specimens. Therefore, the study is aimed to find out the effects of riveting and different overlap lengths on the strength of adhesively bonded joints for polymer-based composite connections. For this purpose, different configurations of double lap joints were created and subjected to tensile tests. As a result of the experiments, the strength of the hybrid connections at different overlap lengths was determined for only adhesively bonded, riveted and a mix of them.

\section{MATERIAL AND METHOD}

In this study, glass fibre reinforced epoxy plates as adherent material and a polyester resin as adhesive were chosen to study the behaviour of the adhesively bonded double lap joints under the static unidirectional loadings. The double lap joints comprising a rivet, adhesive and rivets and adhesives together were created by using glass fibre reinforced epoxy plates (G11 EPGC 203 Hgw 2372.4) having 8 layers and their mechanical properties are given in Table 1.

Table 1. Mechanical properties of G11 EPGC $203 \mathrm{Hgw} 2372.4$, adhesive and rivet

\begin{tabular}{lccc}
\hline Properties & G11 EPGC 203 Hgw 2372.4 & $\begin{array}{l}\text { Adhesive } \\
\text { (Polyester Resin) }\end{array}$ & Rivet (St 37) \\
\hline Tensile Strength & $320 \mathrm{MPa}$ & $3.28 \mathrm{MPa}$ & $370 \mathrm{MPa}$ \\
Flexural Strength & $450 \mathrm{MPa}$ & - & - \\
Compressive Strength & $550 \mathrm{MPa}$ & $39 \mathrm{MPa}$ & - \\
E-Modules & $20 \mathrm{GPa}$ & $210 \mathrm{GPa}$ \\
\hline
\end{tabular}

The three adhesive systems used for joining were 1-double layer polyester bonding, the 2-riveted connection of epoxy composite plates, 3-double layer hybrid bonding. The joining types and overlap lengths of composite specimens were changed to study these effects on the joint strength, failure mechanism as well as on the ultimate joint stress. The adhesive resin was used as a bonding material and its mechanical properties and material behaviour were determined by subjecting bulk specimens, which were manufactured from that adhesive resin to tensile tests according to ISO 527 standards. Stress-strain diagram of the bulk specimens of adhesive material obtained as a result of tensile tests performed is presented in Figure 1. The boundary conditions and dimensions of the manufactured double lap joints in the experimental tests are also illustrated in Figure 2. 
Solmaz et al. / Anadolu Univ. J. of Sci. and Technology A-Appl. Sci. and Eng. 19 (1)-2018

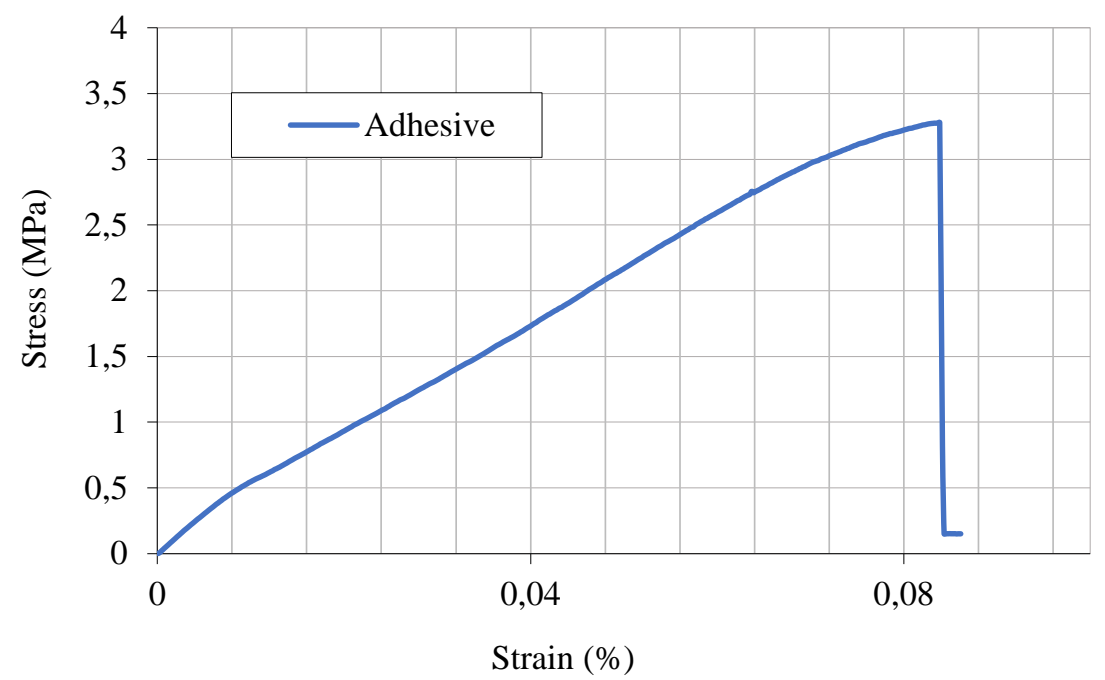

Figure 1. Stress-strain curve for the polyester adhesive.
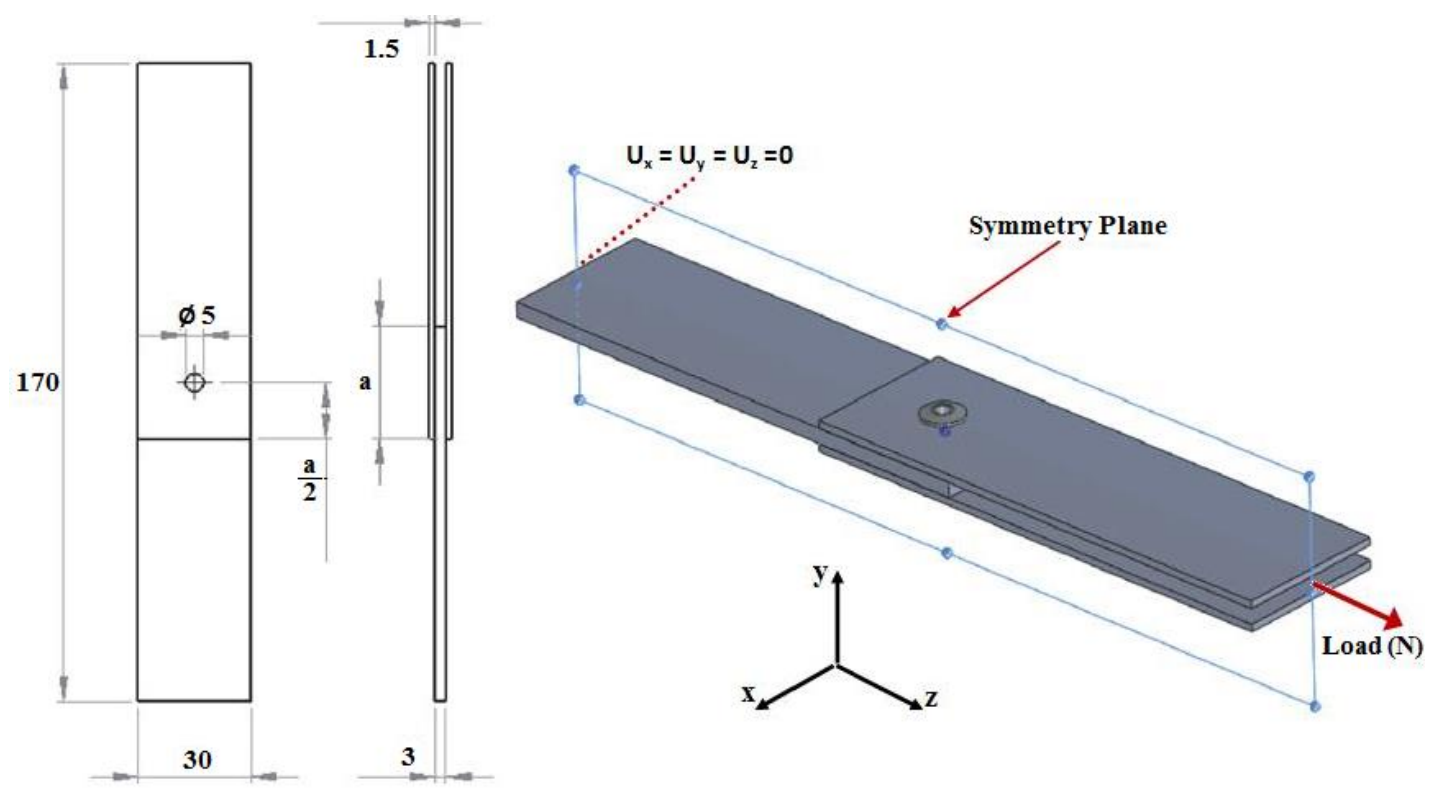

Figure 2. Dimensions of the double lap joints and their experimental boundary conditions.

Overlap regions of the double lap connections were created by three different methods which are adhesive, rivet and both of them. Images of the double lap joints taken before tensile tests for three different connection types (adhesive, rivet, both of them) are presented in Figure 3. 


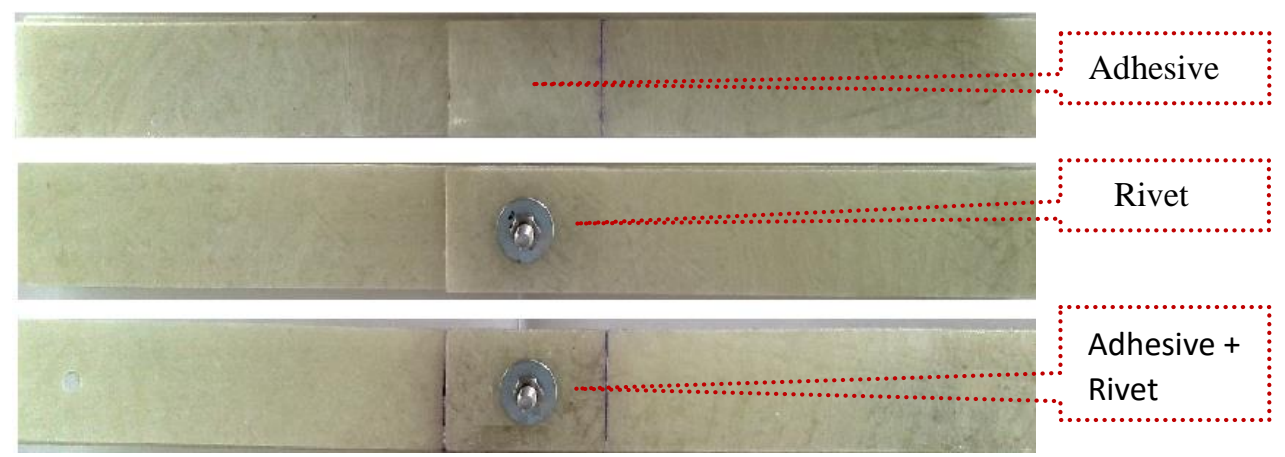

Figure 3. Double lap joint connections created by using adhesive, rivet and together adhesive and rivet at $30 \mathrm{~mm}$ overlap length.

Totally, nine different double lap connections were comprised of three different overlap lengths (30, 45 and $60 \mathrm{~mm}$ ) at three different configurations (adhesive, rivet and adhesive plus rivet) as it can be seen in Figure 3. The most appropriate connection type and overlap length were specified as a result of tensile tests, subjected to the prepared connections, under a constant axial elongation speed of $2 \mathrm{~mm}$ per minute.

\section{RESULTS AND DISCUSSION}

Stress-strain diagrams which were obtained as a result of tensile tests are given in Figure 4 depending on joint configurations and overlap lengths. The joint strengths were determined to be $0.524 \mathrm{MPa}$ for only adhesively bonded and $1.975 \mathrm{MPa}$ for a hybrid joint having the highest joint strength if the overlap length of $30 \mathrm{~mm}$ is taken into account. The joint strength of the hybrid configuration was observed to reach an increase of 377 percent comparing to only adhesively bonded joint at $30 \mathrm{~mm}$ overlap length.

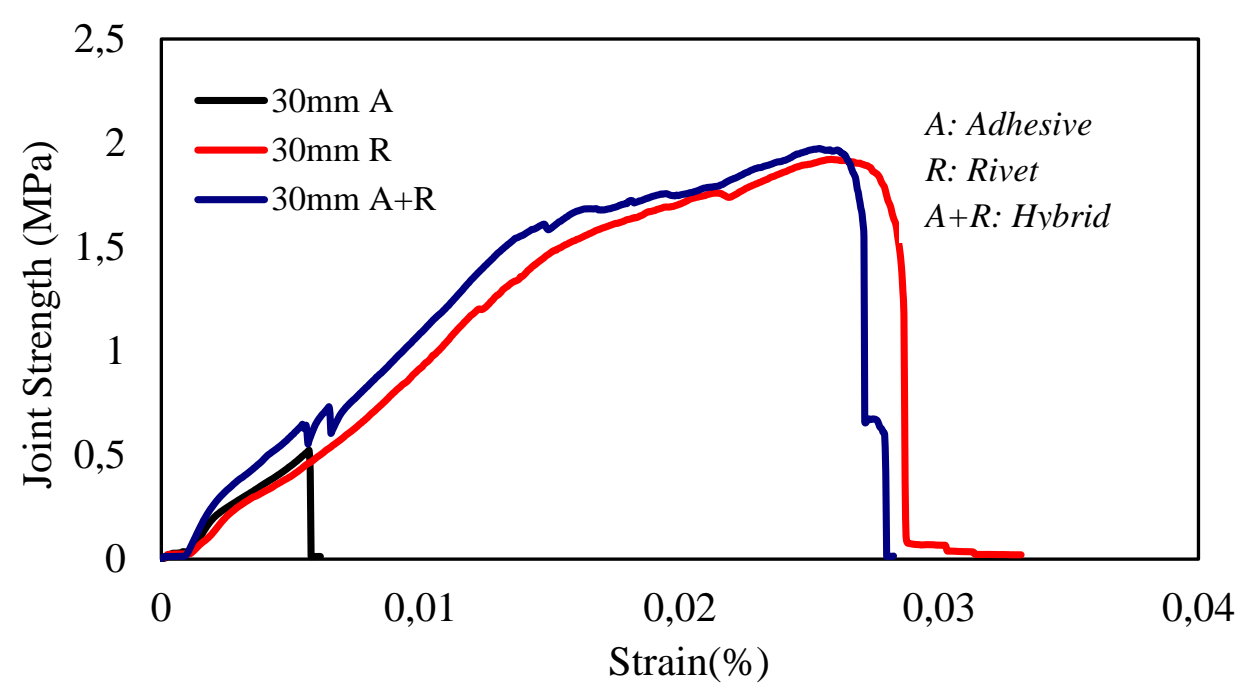

Figure 4. Stress-strain diagram of double lap joints at 30mm overlap length.

In the same way, stress-strain diagrams for $45 \mathrm{~mm}$ overlap length are presented in Figure 5 according to joint types. The joint strength of the connections for only adhesively bonded, riveted and hybrid configuration were determined to be $0.974,2.116$ and $2.512 \mathrm{MPa}$ respectively, at $45 \mathrm{~mm}$ overlap length. Similar to results obtained for $30 \mathrm{~mm}$ overlap length, hybrid joints were found out to have a joint strength which is $258 \%$ and $119 \%$ greater than only adhesively bonded and riveted joint, respectively. 


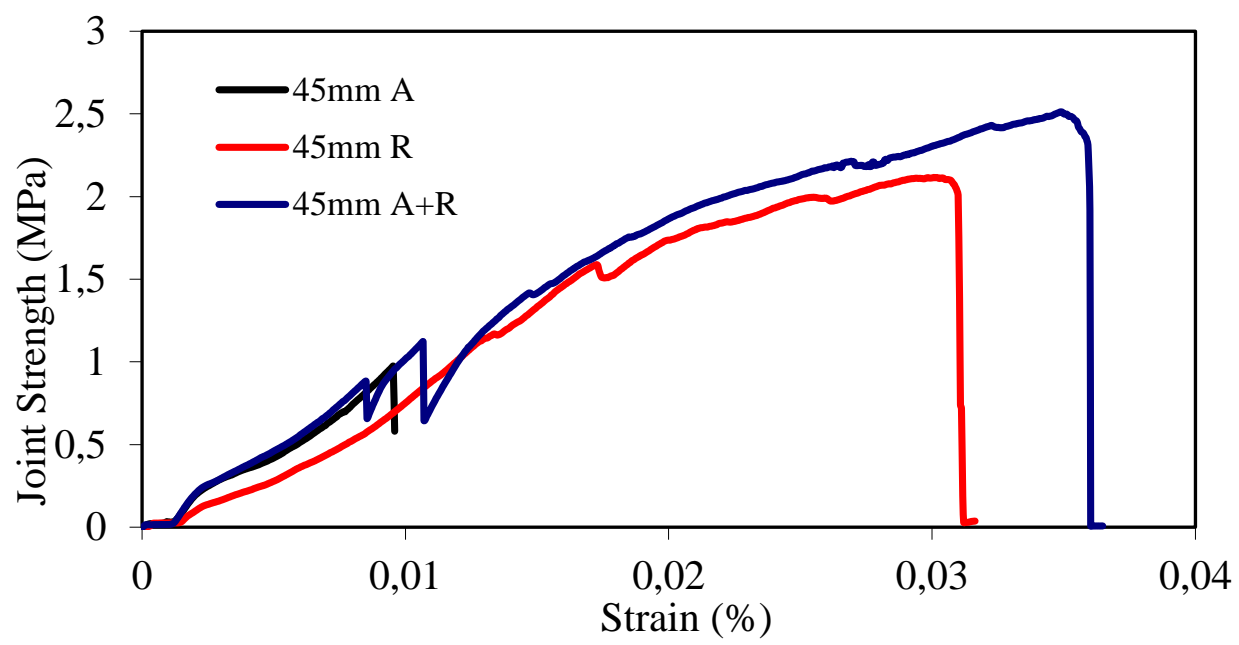

Figure 5. Stress-strain diagram of double lap joints at 30mm overlap length.

For $60 \mathrm{~mm}$ overlap length, stress and strain values at which the double lap joints rupture are shown in Figure 6. Adhesively bonded lap joint was observed to exhibit the weakest strength of $1.258 \mathrm{MPa}$ at $60 \mathrm{~mm}$ overlap length similar to the previous overlap lengths. The joint strength of riveted and the hybrid connection was specified to be $2.119 \mathrm{MPa}$ and $2.773 \mathrm{MPa}$ respectively. If the strength of the hybrid joint is compared to the others, it was achieved to be $217 \%$ and $124 \%$ greater than just adhesively bonded and riveted connection, respectively.

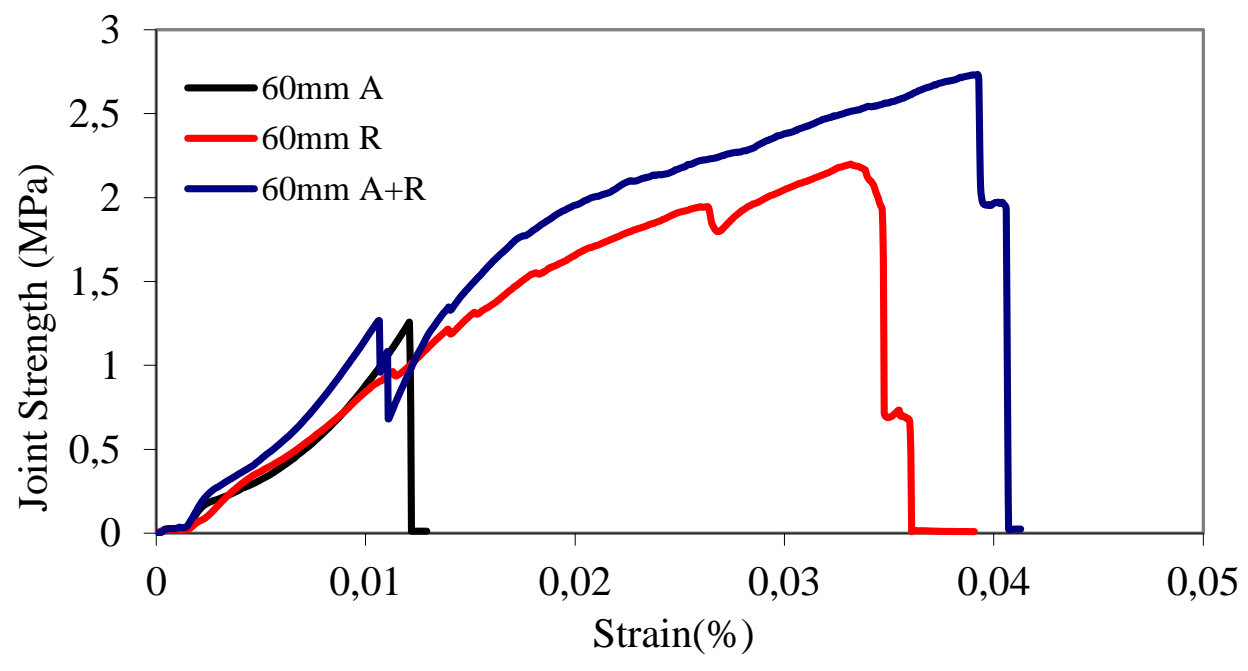

Figure 6. Stress-strain diagram of double lap joints at 60mm overlap length.

Fracture mechanism of all specimens subjected to tensile tests was observed and failure types were tried to be determined. The pictures of connection regions of each joint configuration for 30,45 and $60 \mathrm{~mm}$ overlap lengths taken after tensile tests are presented in Figure 7. Cohesion type of failure was detected in the overlap region of just adhesively bonded joints and the amount of adhesive on the overlap surface of each composite plate was equally scattered while no failure on the contact zones of the composite plates occurred. 
The failure type of riveted joints at $30 \mathrm{~mm}$ overlap length was determined to be shear-out and failure finished as a result of tearing of adhesive in the loading direction (Figure 7a). Accordingly, failure type for the hybrid joints was found out to be net-tension at the same overlap length (Figure 7a).

Net-tension was observed to occur in riveted and hybrid joints at the overlap lengths of 45 and $60 \mathrm{~mm}$ and type of bearing failure was also observed in all the rivet holes taken place on the surface of composite plates [20] (Figure 7b and 7c).

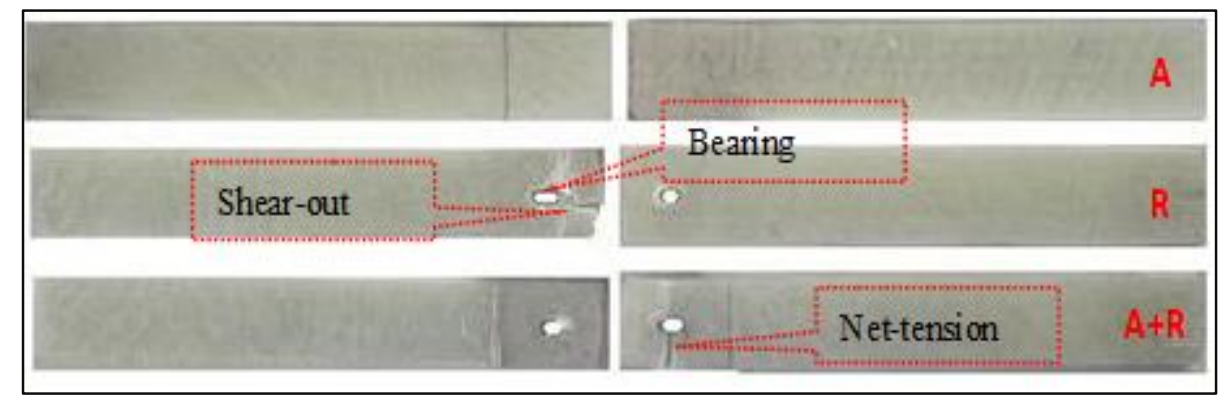

(a)

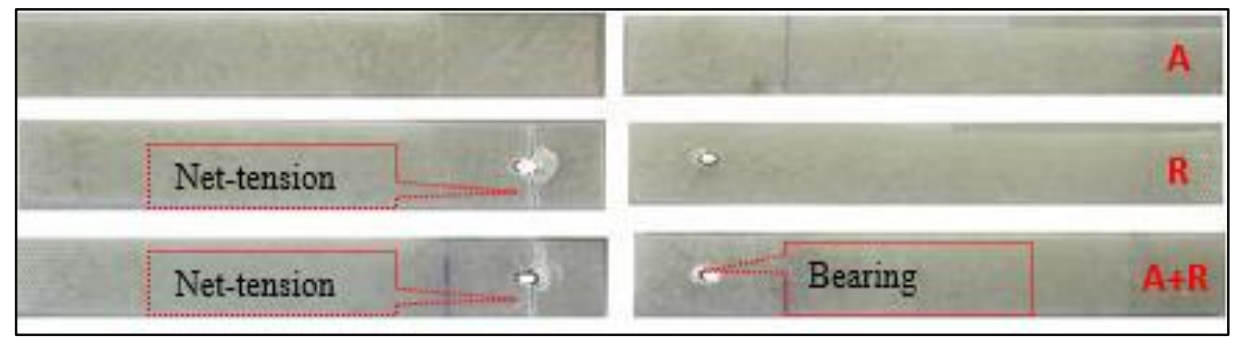

(b)

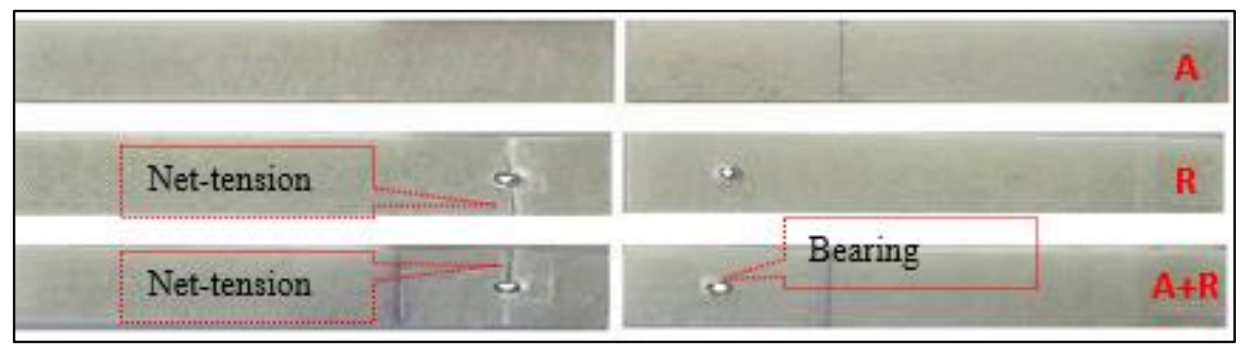

(c)

Figure 7. Overlap lengths for each joint configuration and failure mechanism a) $30 \mathrm{~mm}$ overlap length, b) $45 \mathrm{~mm}$ overlap length and c) $60 \mathrm{~mm}$ overlap length

The highest values of joint strengths obtained according to different joint configurations and overlap lengths are illustrated in Figure 7. As it was seen from the figure, the lowest joint strength was exhibited by adhesively bonded specimens and the highest ones were in hybrid joints. When the experimental results are concerned, the strength values of riveted connections always take place in between the adhesive and hybrid joints.

Increasing the overlap length considerably increased the tensile stress and led to a peak in joint strength as indicated in Figure 8 for all connection configurations. Therefore, the rupture stress of adhesive joint at $30 \mathrm{~mm}$ increase by $240 \%$ corresponding to the increase of overlap length 30 to $60 \mathrm{~mm}$ only led to a substantial recovery in joint strength from 0.524 to $1.258 \mathrm{MPa}$. In the same way, the joint strength of riveted joints also increased by nearly 124 and $126 \%$ corresponding to 2.116 and $2.199 \mathrm{MPa}$ at 45 and $60 \mathrm{~mm}$ overlap length, respectively as it was $1.74 \mathrm{MPa}$ at the beginning (Figure 8). 


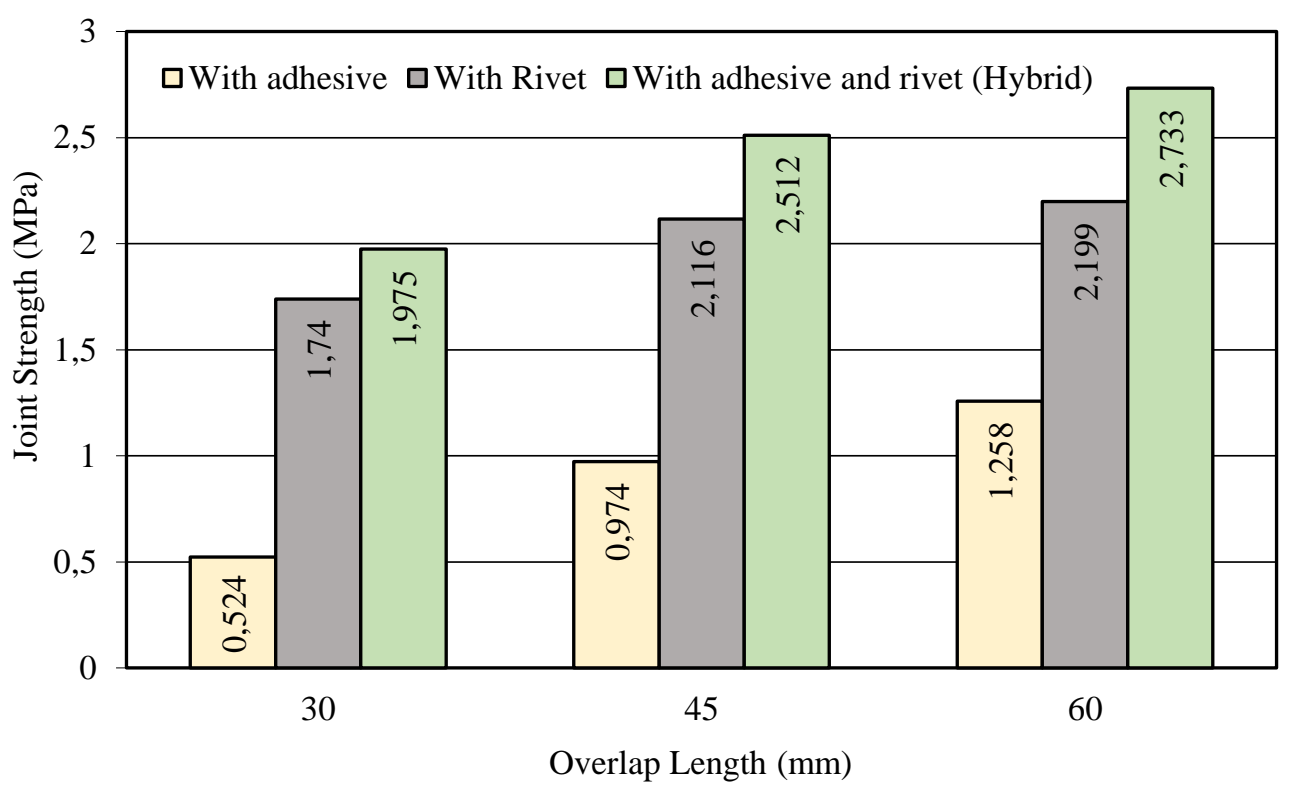

Figure 8. The variation of joint strength depending on the joint system and overlap length

As the effects of overlap length on the strength of hybrid joint was examined, an important improvement has been obtained. In that case, an increase of 127 and $140 \%$ corresponding to 2.512 and $2.773 \mathrm{MPa}$ was achieved at the overlap lengths of 45 and $60 \mathrm{~mm}$, respectively (Figure 8 ). When the joint strengths were compared, the highest difference observed by $521 \%$ between adhesively bonded and hybrid joints corresponding to $30 \mathrm{~mm}$ overlap length.

\section{CONCLUDING REMARKS}

In the present paper, the response of composite double lap joints with polyester adherents subjected to unidirectional tension loads as well as tensile tests was experimentally investigated by means of different joint configurations, including only adhesive, rivet and hybrid joints and results were summarized as follows. The results were verified and compared to the well-known theoretical and experimental results in the literature in the case of the polyester adhesive layer for accuracy as well.

- The joint strength of hybrid system was increased by $377 \%$ corresponding to 30mm overlap length comparing to the adhesively bonded joint system.

- Accordingly, for the change of overlap lengths from 45 to $60 \mathrm{~mm}$, the increase in hybrid joint strength was observed to be nearly 258 and $119 \%$ higher than adhesive and riveted joint as indicated in detail (see Figure 8).

- Adhesive double lap joints show improved properties when the riveted connection was used with adhesives.

- Overlap length of composite double lap joints has a significant effect on the strength and strain to failure values and therefore the toughness of the joint. But the effect on stiffness is not significant.

- The adhesively bonded joints showed brittle failure and cohesion type of failure mechanism occurred. In riveted joints, the failure was specified as bearing and shear-out type of fracture matching $30 \mathrm{~mm}$ overlap length, the others were bearing and net-tension. At hybrid joints, only bearing and net-tension were generated at all overlap lengths [20]. 


\section{REFERENCES}

[1] Custo' dio J., Broughton J., Cruz H., A review of factors influencing the durability of structural bonded timber joints, International Journal of Adhesion \& Adhesives 29 (2009) 173- 185.

[2] Chang-Su Ban, Young-Hwan Lee, Jin-Ho Choi, Jin-Hwe Kweon, Strength prediction of adhesive joints using the modified damage zone theory, Composite Structures 86 (2008) 96-100.

[3] Choi JH, Lee DG. An experimental study of the static torque capacity of the adhesively-bonded tubular single lap joint. J Adhesion 1996; 55:245-60.

[4] Adams RD, Comyn J, Wake WC., Structural adhesive joints in engineering. London: Chapman \& Hall;1997.

[5] M. Arenas J, J.Narbo'n J, Al1' C, Optimum adhesive thickness in structural adhesives joints using statistical techniques based on Weibull distribution, International Journal of Adhesion \& Adhesives 30 (2010) 160-165.

[6] Reis PNB, Antunes FJV, Ferreira JAM. Compos Struct 2004;67:125.

[7] S.M.R. Khalili, S. Khalili, M.R. Pirouzhashemi, A. Shokuhfar, R.K. Mittal, Numerical study of lap joints with composite adhesives and composite adherends subjected to in-plane and transverse loads, International Journal of Adhesion \& Adhesives 28 (2008) 411- 418.

[8] Goglio L, Rossetto M, Precision of the one-dimensional solutions for bonded double lap joints, International Journal of Adhesion and Adhesives 31 (2011) 301-314.

[9] Park YB, Song M-G, Kim J-J., Kweon J-H, Choi J-H., Strength of carbon/epoxy composite singlelap bonded joints in various environmental conditions, Composite Structures 92 (2010) 2173-2180.

[10] Harris JA, Adams RD. Strength prediction of bonded single lap joints by nonlinear finite element method. Int J Adhes Adhes 1984;4:65-78.

[11] Hart-Smith LJ. Adhesive-bonded double-lap joints. NASA CR-112235. National Aeronautics and Space Administration; 1973.

[12] Tong L. Bond strength for adhesive-bonded single-lap joints. Acta Mech 1996;117:101-13.

[13] Tong L. Strength of adhesively bonded single-lap and lap-shear joints. Int J Solids Struct 1998; 35:2601-16.

[14] Suo Z, Hutchinson JW. Interface crack between two elastic layers. Int J Fract 1990;43:1-18.

[15] Kafkalidis MS, Thouless MD. The effects of geometry and material properties on the fracture of single lap-shear joints. Int J Solids Struct 2002; 39:4367-83.

[16] Lai YH, Rakestraw MD, Dillard DA. Cracked lap shear specimen revisited - a closed form solution. Int J Solids Struct 1996; 33:1725-43.

[17] Shahin K., Taheri F., Deformations in adhesively bonded joints on elastic foundations, Composite Structures 90 (2009) 130-140. 
Solmaz et al. / Anadolu Univ. J. of Sci. and Technology A-Appl. Sci. and Eng. 19(1)-2018

[18] Song MG, Kweon JH, Choi JH., Byun JH, Song MH, Shin SJ, Lee TJ, Effect of manufacturing methods on the shear strength of composite single-lap bonded joints, Composite Structures 92 (2010) 2194-2202.

[19] Apalak ZG, Apalak MK. Progressive damage modeling of and adhesively bonded unidirectional composite single-lap joint in tension at the mesoscale level. J Thermoplast Compos Mater 2006; 19:671-702.

[20] İçten BM, Oktan B, Karakuzu R. Failure strength of woven glass fiber-epoxy Composites Pinned Joints. Journal of Composite Materials 37 (2003); 1337-1350. 